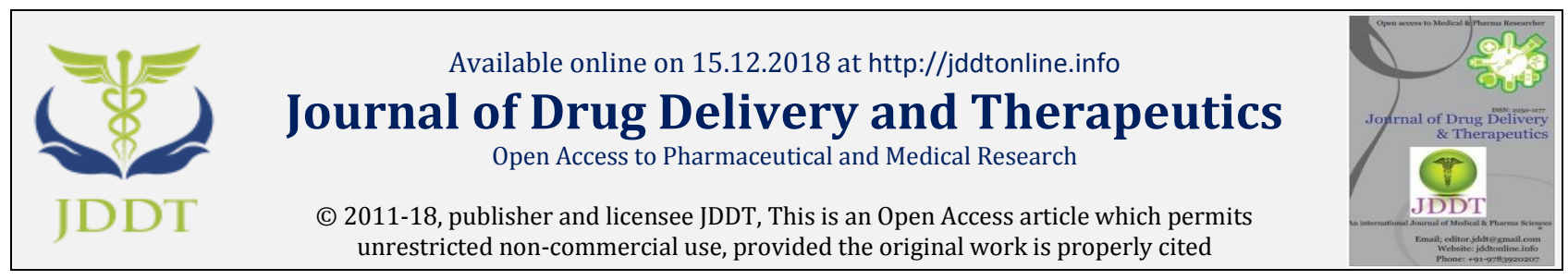

Open $\odot$ Access

Review Article

\title{
Co-Crystals: A Review
}

\section{Chaudhari Shilpa *, Nikam Sarika, Khatri Neetu, Wakde Shubham}

Dr. D. Y. Patil College of Pharmacy, Akurdi, Pune- 411 044, Maharashtra, India

\begin{abstract}
In development of new product major constraints are poor aqueous solubility and low oral bioavailability. Crystallization is one the approach has been used for enhancement of solubility of poorly aqueous soluble drugs also helps to improve physicochemical properties such as melting point, tabletability, solubility, stability, bioavailability and permeability with preserving the pharmacological properties of the active pharmaceutical ingredient. Different methods have been used for the synthesis of cocrystal such as grinding, slurry, antisolvent, hot melt extrusion, sonocrystallization, supercritical fluid, spray drying etc. The article highlights the co-crystallization, its methods and significance.
\end{abstract}

Keywords: Pharmaceutical Co-crystals, Co-crystallization, solubility, stability, bioavailability, Grinding, Slurry conversion, Solvent evaporation.

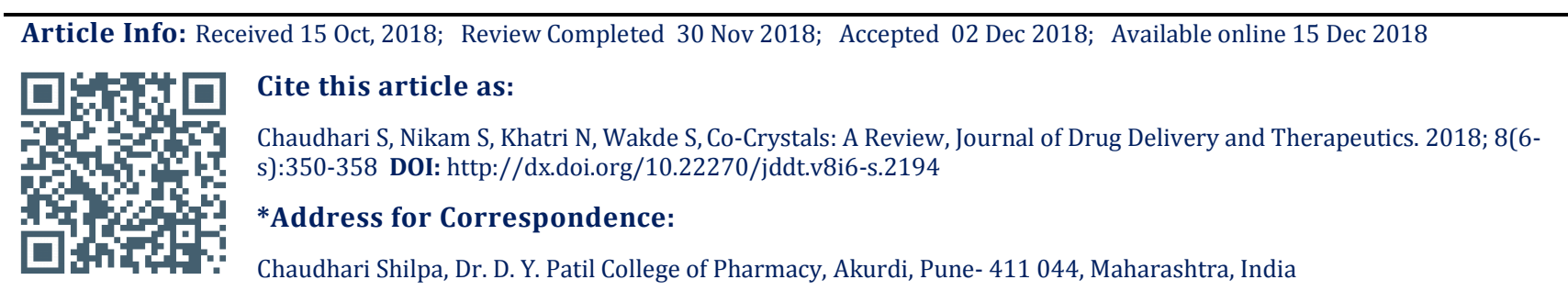

\section{INTRODUCTION}

From recently discovered large numbers of drugs around $60-70 \%$ are related to the BCS Class II (low solubility/high permeability) and IV (low solubility/ low permeability) ${ }^{1}$ and cause difficulty related to dissolution, solubility, stability, therapeutic efficacy etc. ${ }^{2}$. Need of today's era is to decrease problems regarding solubility and permeability of available drugs with different methods. Multi-component crystals like solvates, hydrates, co-crystals, salts contribute key role in the design of new solids mainly in the pharmaceutical area.

\section{Cocrystals:}

Crystallization is defined as alteration of physical properties of by modifying drug at molecular level. Process of Cocrystallization requires drug and coformer for formation of cocrystal.

Cocrystals are multicomponent molecular crystals where all components are at a stoichiometric ratio and comprise of two or more chemically different molecules includes modification of drugs to alter physical properties of a drug, especially a drug's solubility without altering its pharmacology effect. $3,4,5$

\section{Implications of cocrystals:}

Cocrystallization is defined as alteration of physical properties of by modifying drug at molecular level means one can tailored physicochemical properties of drugs to improve it by mans of various methods enlisted blow, so there is no need to any other additives to improve physicochemical property of substances ${ }^{11}$. APIs and conformers properties, nature of molecular interaction between them and synthetic procedures are important factors in altering only physicochemical properties but not alter pharmacological properties. The effect on the physicochemical properties of the API is dependent on the available coformer ${ }^{12,13}$.

Pharmaceutical cocrystals can enhance the physicochemical properties of drugs like melting point, tabletability, solubility, stability, bioavailability, permeability and these properties are highlighted here with suitable examples.

\section{Melting point:}

It is one of the physical properties of solid and used for determination of purity. Pure substances or solid melt at sharp meting point with narrow range ${ }^{15}$. Thermodynamic stability of any API can be govern by its meting point so utility of high melting point conformer for its better stability and also useful in case of thermolabile drugs, so selection of conformer is very important in case of synthesis of cocrystals ${ }^{16}$. Differential scanning calorimetry (DSC) and thermal gravimetric analysis (TGA) are most common techniques used to determine melting point. Zhang et al studied synthesis of Carbamazepine Cocrystal by using Nicotinamide and saccharin as conformer in two different solvents like ethanol-water solvent mixture and polyvinyl pyrrolidone (PVP) solution. Author studied melting point of cocrystal with the help of differential scanning colorimetry and observed that in case of DSC curve of starting material that is carbamazepin and nicotinamide in ethanol water mixture showed melting around $195^{\circ} \mathrm{C}$ and $132^{\circ} \mathrm{C}$, respectively. And cocrystals 
formed showed single endothermal peak is around $162^{\circ} \mathrm{C}$, which was located between the melting point of carbamazepin and nicotinamide, while carbamazepine and saccharin in ethanol water mixture showed melting around 176 and $181^{\circ} \mathrm{C}$ and cocrystals formed showed melting point at $173^{\circ} \mathrm{C}^{17}$. Jadhav et al (also studied melting point study of fenofibrate cocrystals formed with different conformers like para amino benzoic acid, benzoic acid and salicylic acid and observed that melting point of pure fenofibrate was at $78-82^{\circ} \mathrm{C}$ and melting points of conformers like para amino benzoic acid, benzoic acid and salicylic acid was $184-186^{\circ} \mathrm{C}, 158-160^{\circ} \mathrm{C}, 122-124^{\circ} \mathrm{C}$ respectively, while conformers formed showed melting point at $76-78^{\circ} \mathrm{C}, 74-76^{\circ} \mathrm{C}, 70-72^{\circ} \mathrm{C}$ respectively. Author concluded that melting point of fenofibrate was decreased than pure one and individual conformers ${ }^{18}$. Author synthesized Cocrystal of Piroxicam using sodium acetate, saccharine sodium Urea, Nicotinamide, resorcinolas conformer and studied difference in melting point of drug and cocrystals. Melting point of sodium acetate, saccharine sodium coformers were high previously but after forming cocrystal with Piroxicam it get decreased, while melting point of cocrystal of Urea, Nicotinamide, resorcinol was increased 19

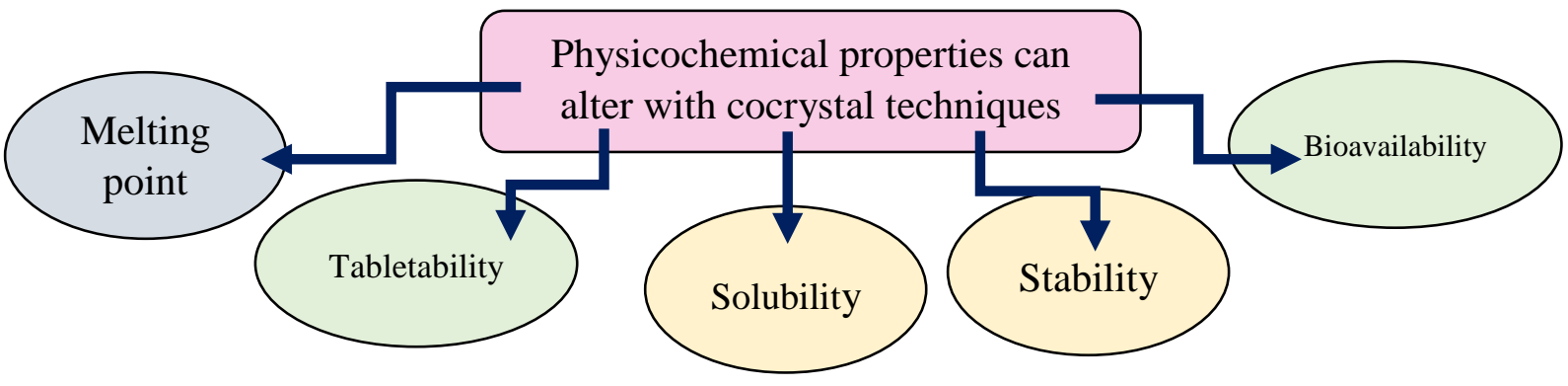

\section{Tabletability:}

Tabletability means ability of substance to get covert in tablet form. Crystal packing, tabletability and compaction are important parameters of preformulation study; with help of cocrystallization we can alter these properties by using suitable conformers. Zheng zheng et al synthesized cocrystals of Resveratrol with conformers 4aminobenzamide and isoniazid and studied its enhanced solubility and tabletability. Author observed that tabletability of RES is poor and because of this even at high pressure that is $0.6 \mathrm{MPa}$ and lamination of tablets, while tablets prepared with cocrystals of Resveratrol-4aminobenzamide, tensile strength more than $3 \mathrm{MPa}$ is attained at $250 \mathrm{MPa}$ compaction pressure. Author concluded that cocrystal formation improved tabletability of drug. Compaction behavior of cocrystals of paracetamol with trimethylglycine and oxalic acid was found to be better than pure drug. Tabletability of resveratrol was enhanced by formation of cocrystals with 4aminobenzamide and isoniazid. Cocrystals showed higher tabletability than either pure drug or coformers. Mechanical properties of APIs could be altered by varying crystal packing by cocrystallization and cocrystals of vanillin isomers with same coformer showed higher tabletability than isomers and coformer ${ }^{20}$. Paracetamol have poor compression property, to overcome this problem normally we use wet granulation method for preparation of paracetamol tablet and this is very tedious job, so to resolve this problem Latif et al. synthesized paracetamol cocrystals to improve compaction or tabletability of paracetamol. Author prepared cocrystal of paracetamol by using caffine as conformer by methods like dry grinding; liquid assisted grinding, solvent evaporation, anti-solvent addition and observed that the compaction power and mechanical property of paracetamol has been increased 21 .

\section{Solubility:}

As discussed in introduction about 60 to $70 \%$ drugs are belongs to BCS Class II (low solubility/high permeability) and IV (low solubility/ low permeability) ${ }^{1}$, so its need to improve solubility of these drugs to develop the various formulations. With development of cocrystal one can increase the solubility of lo soluble drug many researchers have been improved solubility of drug with this technique. For eg. Mounika et al. developed cocrystals of Fexofenadine by using Tartaric acid as conformer by solvent evaporation technique and studied cocrystals for saturation solubility according to the method of Higuchi and Connors. Author performed drug solubility study with water as well as 0.01 $\mathrm{N} \mathrm{HCl}$ and observed that solubility of Co-crystals in water is increase with 11 folds more than the pure drug and solubility of Co-crystals in $0.01 \mathrm{~N} \mathrm{HCL}$ is 2.47 folds more than the pure drug22. Iyan et al developed Simvastatinnicotinamide co-crystals by solvent evaporation to improve the solubility of simvastatin by co-crystallization using nicotinamide as co-crystal agent or co-former and evaluated for solubility. Observation was saturated solubility of co-crystal show a threefold increase compared to raw simvastatin ${ }^{23}$. Chadha et al also improved solubility of efavirenz by cocrystal technique. Author synthesized cocrystals of efavirenz by using oxalic acid dihydrate and citric acid monohydrateas conformers to improve a physicochemical property that is solubility and dissolution rate. As both conformers have high water solubility that is $14.3 \mathrm{~g} / 100 \mathrm{ml}$ and $64.7 \mathrm{~g} / 100 \mathrm{ml}$ respectively and contain hydrogen bond donor and acceptor groups, which can be used for designing cocrystals of efavirenz leading to improvement in solubility ${ }^{24}$. Shubhangi et al synthesized cocrystals of poorly water soluble drug Darunavir. It is BCS Class II drug having low solubility. Co crystals were developed by cooling crystallization method using succinic acid as conformer. Author determined aqueous solubility of darunavir by saturation solubility by dissolving excess amount of cocrystals in water for $24 \mathrm{hrs}$ on the rotary shaker, analyzed with spectrophotometer and observed that with Cocrystallization technique there is significant improvement in the aqueous solubility, found 1.92 fold increases in saturation solubility ${ }^{25}$. Author Rajurkar also developed Co Crystals of Ezogabine to improve Aqueous Solubility using carboxylic acids as conformer by grinding; ultrasound assisted co-crystallization and solvent evaporation techniques and found that 10-11 fold improvement in solubility of co crystals than pure drug 26 . Muddukrishna et al studied synthesis of paclitaxel and naringen cocrystal to improve solubility by solvent assisted grinding method. Paclitaxel (PTX) is a class-4 drug; this drug has low aqueous solubility. Solubility study 
of paclitaxel and naringen cocrystal was done at room temperature for 72 hours by shake flask method, analyzed samples with HPLC method and found 2.4 fold increases in the saturation solubility27. Prabhakar et al also prepared Cocrystal of Piroxicam and studied for solubility. Author used various conformers like adipic acid, benzoic acid, cinnamic acid, citric acid, glutaric acid, phydroxybenzoic acid, hippuric acid, malonic acid, resorcinol, saccharine sodium, 1-hydroxy-2- napthoic acid, sodium acetate, urea, catechol, ferulic acid, aerosil-200, nicotinamide, para amino benzoic acid, anthranilic acid and succinic acid for synthesis of cocrystals and performed saturated aqueous solubility of cocrystal and found significant increase in solubility of drug after formulating as cocrystals [28]. Muddukrishna Co-Crystals of Etraverine to improve Solubility by using Tartaric Acid as conformer with slow evaporation technique. Etravirine is a BCS Class IV drug having lo solubility and low permeability. Solubility study of cocrystals was done by shake flask method and found 3.6 fold increase in solubility of cocrystals than pure drug29.

\section{Stability:}

It is also imperative study has to be done during the development of new dosage formulation. Different stability studied like chemical stability, thermal stability, solution stability and photostability should be performed during development of pharmaceutical cocrystals. Iyan 23 et al developed Simvastatin-nicotinamide co-crystals by solvent evaporation to improve the solubility of simvastatin by cocrystallization using nicotinamide as co-crystal agent or coformer and evaluated for stability study at $40^{\circ} \mathrm{C}$ and relative humidity (RH) 75\% in one month found it stable.

\section{Bioavailability:}

Bioavailability is defined as the rate and extent of pure drug that reaches into systemic circulation. Low oral bioavailability of APIs is one of the major challenges in development of formulations, with help of cocrystallization one can enhance or improve the bioavailability of drug. Many researchers has been enhanced the bioavailability of different drugs with conversion in cocrystal form. For eg. Mounika et al prepared cocrystals of Fexofenadine. Fexofenadine is class II drug according to the BCS classification with low solubility and high permeability, the rate limiting steps in attaining desired bioavailability. Hence Author prepared cocrystals of Fexofenadine using Tartaricacid as a co-former by solvent evaporation and observed that with cocrystallisation technique drug hoed maximum release as compared to the formulation ${ }^{22}$. Pinky et al formulated cocrystals tablets dosage form of clarithromycin to enhance the bioavailability. As Clarithromycin is BCS Class II drug author prepared cocrystals by using urea as conformer by solvent evaporation method. Developed tablet formulation and evaluated. Author concluded that the formulated tablets of Clarithromycin co-crystals showed improved solubility and in-vitro drug release profile as compared to Marketed Tablet. And thereby increases oral bioavailability and therapeutic effect 35 . Zhang et al studied synthesis of Carbamazepine Cocrystal by using Nicotinamide and saccharin as conformer by solvent evaporation technique ${ }^{36}$.

\section{Methods of Preparation:}

Co-crystal formation described in the literature indicates the notoriously difficult situation these systems present with regard to preparation it has been known to take 6 months to prepare a single co-crystal of suitable quality for single X-ray diffraction analysis. This is partly because such a heteromeric system will only form if the non-covalent forces between two (or more) molecules are stronger than between the molecules in the corresponding homomeric crystals. Design strategies for co-crystal formation are still being researched and the mechanism of formation is far from being understood.

Co-crystals can be prepared by solvent and solid based methods. The solvent-based methods involve slurry conversion solvent evaporation, cooling crystallization and precipitation. The solid based methods involve net grinding; solvent-assisted grinding and sonication (applied to either to wet or dry solid mixtures) 80 to $85^{\circ} \mathrm{C}$.

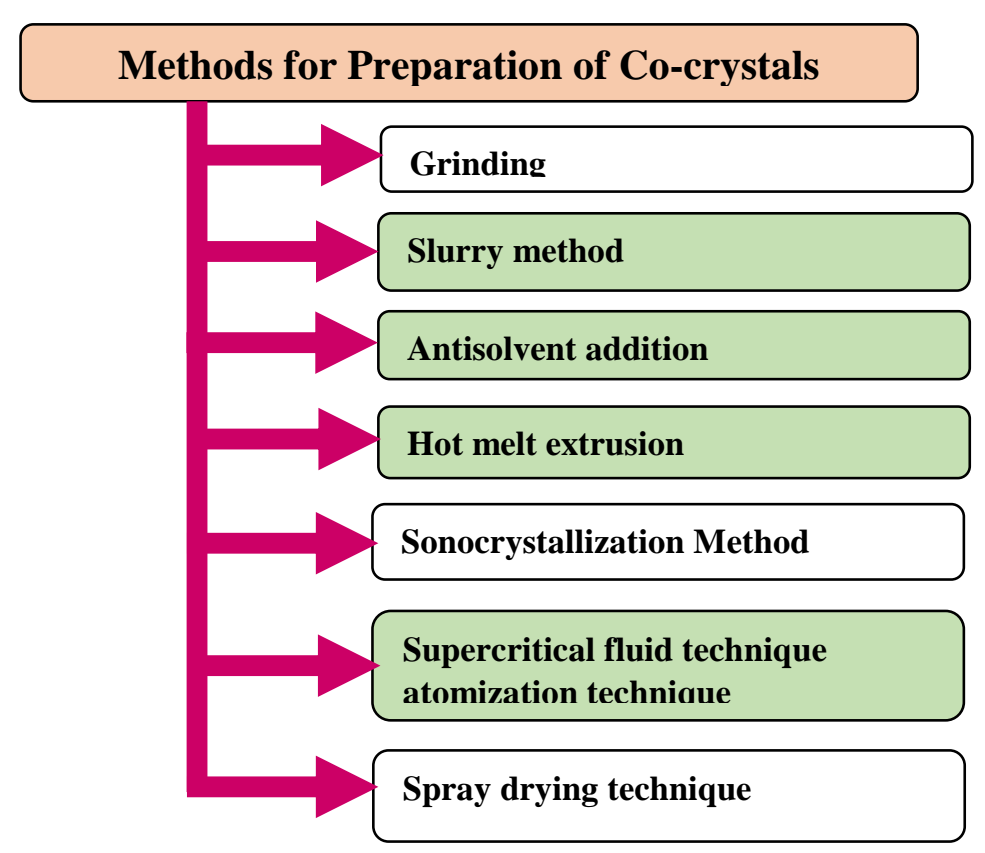

Figure 1: Methods of preparation of cocrystals 
Grinding:

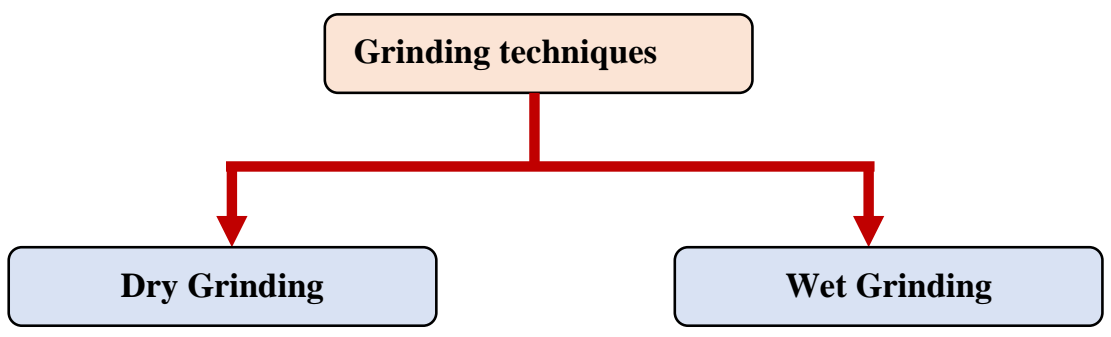

Figure 2: Grinding techniques for preparation of cocrystals

\section{Dry Grinding: (Pharmaceutical Cocrystals: An Overview)}

\author{
Drug + Coformer \\ (In a stoichiometric ratio) \\ 1 Grind
}

(Mortar and pestle or ball mill)

\section{Wet Grinding:}

Drug + Coformer

(In a stoichiometric ratio)

$$
\text { Grind } \begin{gathered}
\text { Addition of some drops of } \\
\text { solvent in mixture }
\end{gathered}
$$

(Mortar and pestle or ball mill)

Cocrystals have been synthesized by grinding method Sungyup et al prepared Adefovir dipivoxil Co-crystals by using glutaric acid and suberic acid as conformer by liquidassisted grinding ${ }^{37}$, Prabhakar et al synthesized Cocrystal of Piroxicam by dry grinding method, sodium acetate used as conformer. Author reported modified properties of piroxicam cocrystal and formulated orodispersible tablets having faster disintegration and greater dissolution rate. Ibuprofen-amino acids co-crystal screening via co-grinding methods ${ }^{28}$. Muhamad et al synthesized Ibuprofen-amino acids cocrystals by dry grinding as well as liquid assisted grinding method ${ }^{38}$. Gaikwad et al studied synthesis of cocrystals of Fenofibrate by grinding method 39

\section{Slurry conversion:}

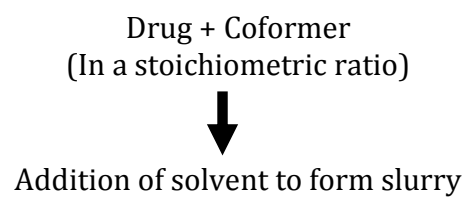

Slurry conversion experiments were conducted in different organic solvents and water. Solvent (100 or $200 \mathrm{ml}$ ) was added to the co-crystal $(20 \mathrm{mg})$ and the resulting suspension was stirred at room temperature for some days. After some days, the solvent was decanted and the solid material was dried under a flow of nitrogen for $5 \mathrm{~min}$. The remaining solids were then characterized using PXRD. For eg DWI et al reported synthesis of nicotinamide cocrystal by slurry method. Author mixed both powders of Artesunate and nicotinamide homogeneously in mortar and added water to the mixture to form slurry ${ }^{40}$. Noriyuki et al studied synthesis of corystals of stanolone and mestanolone using slurry crystallization ${ }^{41}$. Prafulla et al synthesized caffeine/maleic acid co-crystal by ultrasoundassisted slurry co-crystallization techniques ${ }^{42}$. Erizal et al prepared cocrystals of trimethoprim and sulfamethoxazole by slurry technique. Cocrystallization was formed by simply adding water as solvent to mixture of trimethoprim and sulfamethoxazole and developed cocrystals was characterized by thermomicroscopy, scanning electron microscope, powder X-ray diffraction, differential scanning calorimetry. Author also studied effect of temperature on formation of cocrystal and observed that transformation to cocrystalline phase was accelerated by increasing the temperature of storage 43 .

\section{Antisolvent addition:}

This is one of the methods for precipitation or recrystalization of the co-crystal former and active pharmaceutical ingredient. Solvents include buffers $(\mathrm{pH})$ and organic solvents. For example preparation of cocrystals of aceclofenac using chitosan, in which chitosan solution was prepared by soaking chitosan in glacial acetic acid. A weighed amount of the drug was dispersed in chitosan solution by using high dispersion homogenizer. This dispersion was added to distilled water or sodium citrate solution to precipitate chitosan on drug. Momoko et al studied synthesis of co-crystals by Antisolvent addition method by two sequences ${ }^{44}$.

\section{First sequence was:}

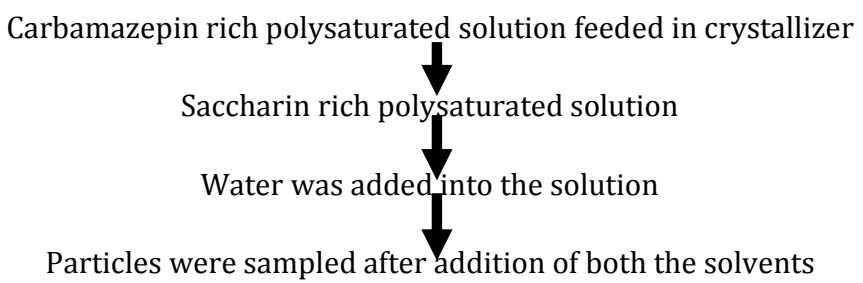


Second sequence was:

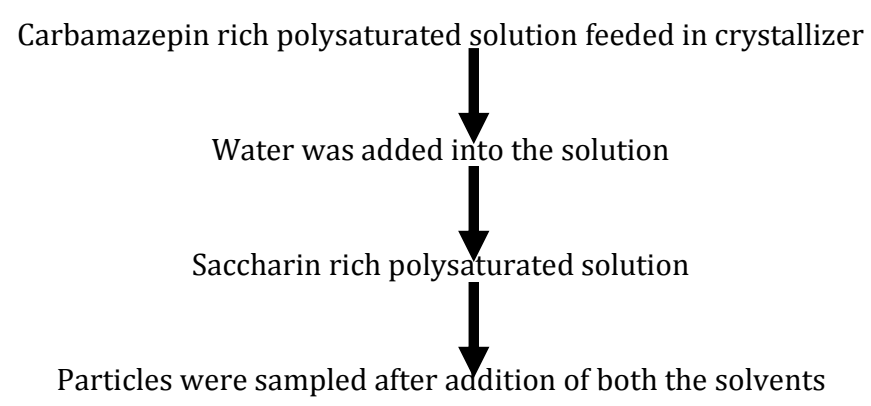

And characterized sample by X-ray diffraction (XRD) analysis. While Jeong et al and Nan-Hee et al prepared indomethacin-saccharin co-crystals by an anti-solvent crystallization process and compared with co-crystals by evaporation method 45,46 .

\section{Hot melt extrusion}

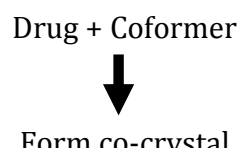

Form co-crystal

Hot melt extrusion drug and coformers are heated with intense mixing without addition of solvent, for eg $\mathrm{Li}$ et al, synthesized ibuprofen/isonicotinamide cocrystal suspensions single-step hot-melt extrusion process ${ }^{47}$. Kevin et al studied synthesis of Carbamazepine Cocrystals by Hot-Melt Extrusion author used Carbamazepine as the drug and nicotinamide used as conformer and characterized cocrystal matrix by differential scanning calorimetry, Fourier transform infrared spectroscopy, and powder X-ray diffraction 48 .

\section{Sonocrystallization Method ${ }^{49}$ :}

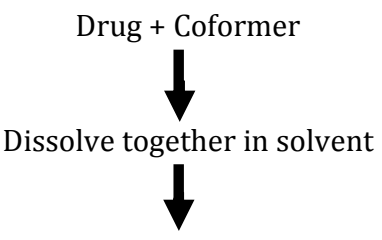

Keep for sonication at constant temperature

Heating with intense mixing without addition of solvent

\begin{abstract}
Several researchers studied preparation of cocrystals by sonocrystallization method Prafulla et al studied synthesis of corystals of Caffeine/Maleic Acid by Ultrasound-assisted Slurry Co-crystallization. Author constructed two phase diagram that is one in the absence of and one in the presence of ultrasound, prepared slurry by varying quantity of amounts of caffeine, maleic acid, and water and other one was subjected to 12 ultrasound pulses of $5 \mathrm{~s}$ each separated by a gap of $1 \mathrm{~s}$, using a 20$\mathrm{kHz}$ high-power ultrasound set at $50 \%$ amplitude at $25^{\circ} \mathrm{C}^{50}$.
\end{abstract}

\section{Supercritical fluid atomization technique [Supercritical Antisolvent (SAS) Method]:}

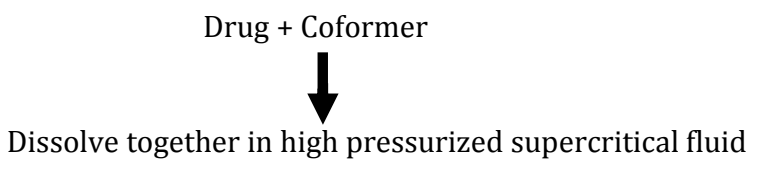

$\underbrace{\left(\mathrm{CO}_{2}\right)}$

Automize the solution with automizer at normal temperature and pressure causes conversion of $\mathrm{CO}_{2}$ from liuid state to gas

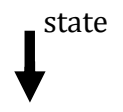

Formation of co-crystals
Abhijat et al prepared and characterized Carbamazepine and Nicotinamide co-crystals by supercritical fluid process (SCF) method and characterized developed cocrystals by dissolution studies, differential scanning calorimetry, hot stage microscopy, scanning electron microscopy, H NMR and X-ray powder diffraction ${ }^{51}$. Courtney et al studied synthesis of Cocrystals of itraconazole and succinic acid by gas antisolvent (GAS) cocrystallization using pressurized
$\mathrm{CO}_{2}$. Author dissolved itraconazole and succinic acid in a liquid solvent (tetrahydrofuran) at ambient conditions and pressurized solution with $\mathrm{CO}_{2}$, which decreased the solvating power of tetrahydrofuran and caused crystallization of itraconazole-succinic acid cocrystals. Chaqrecterized cocrystals by Powder X-ray diffraction, Fourier transform infrared spectroscopy, differential scanning calorimetry, and scanning electron microscopy 52 . 


\section{Spray drying technique:}

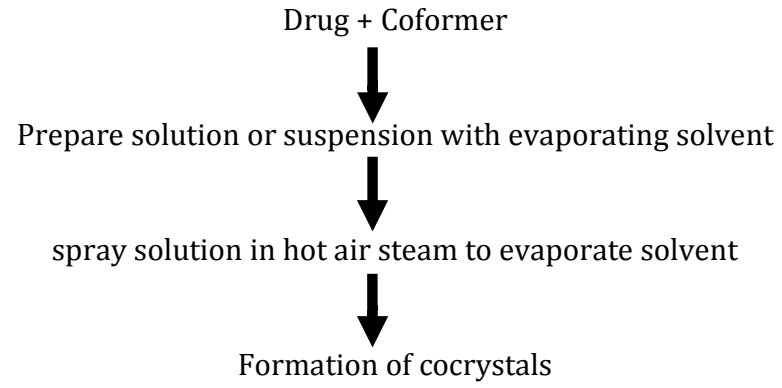

Ning et al synthesized cocrystals of 2,4,6,8,10,12 hexanitrohexaazaisowurtzitane (CL-20) and 2,4-dinitro-2,4diazapentane (DNDAP) in a 2:1 molar ratio by a rapid and continuous spray drying method spray drying method 53 . Amjad et al synthesized Theophylline Cocrystals by Spray Drying technique. Author prepared Cocrystals of Theophylline with urea and saccharin with nicotinamide by spray drying by using various solvents and solution concentrations while dying was done with nitrogen gas ${ }^{54}$.

\section{CHARACTERIZATION OF CO-CRYSTALS:}

Characterization of co-crystals includes study of structural and physical properties $55,56,57,58$.

Following are the techniques for the characterization of cocrystals used by different authors for characterization.

\section{Structural:}

Infrared spectroscopy,

Single crystal x-ray crystallography and

powder x-ray diffraction
Physical: 55, 56

Melting point apparatus,

Differential scanning calorimetry,

Thermogravimetric analysis

XD method is generally used for to determine structure of cocryatal. XRD study includes single crystal evaluation as well as powder XRD. No. of researchers have used this technique for characterization of cocrystals. Thermal analysis also one of the technique used for the characterization of cocrystals. For cocrystal Thermal techniques like characterization thermogravimetric analysis and differential thermal analysis and differential scanning colorimetry are generally used. Spectroscopy methods are also used to characterize cocrystals like vibrational spectroscopy and nuclear magnetic resonance. NMR is a powerful characterization tool that can provide detailed information on the structure of organic pharmaceutical cocrystals and complexes 59,60 . Raman spectroscopy also one of the tool used for observation of crystallization process. It is used to differentiate between polymorphs, salts, cocrystals, solid solutions and hydrated salts ${ }^{61}$. Fourier-transform Raman is also used to for the identification and quantitative analysis of cocrystals ${ }^{62}$. Zhang et al prepared cocrystals of carbamazepine and characterized same with Fourier Transform Infrared Spectroscopy (FTIR), Differential Scanning Calorimetry (DSC), and Powder X-ray Diffraction (PXRD) techniques ${ }^{63}$ shahram et al synthesized piroxicam cocrystals and evaluated them using powder X-ray diffraction, Fouriertransform infrared spectroscopy, DSC etc ${ }^{64}$ Desai et al also prepared Carbamazepine Cocrystals by Solvent Evaporation Technique and evaluated them for Visual morphology, differential scanning calorimetry, infrared spectroscopy, x-ray diffractometry etc ${ }^{65}$.crystals of piracetam and gentisic acid prepared by slow evaporation were characterized by IR, melting point, DSC, PXRD and single crystal X-ray diffraction ${ }^{66}$.

Table 1: Reported Methods of Co-Crystals

\begin{tabular}{|l|l|l|l|}
\hline Drug & Co-former & Method used to prepare & Ref. \\
\hline Piroxicam & $\begin{array}{l}\text { Adipic Acid, Benzoic Acid, Cinnamic Acid, Citric Acid, Glutaric } \\
\text { Acid, P-Hydroxybenzoic Acid, Hippuric Acid, } \\
\text { Malonicacid,Resorcinol, Saccharine Sodium, 1-Hydroxy-2- } \\
\text { Napthoic Acid, Sodium Acetate, Urea, Catechol, Ferulic Acid, } \\
\text { Aerosil-200, Nicotinamide, Para Amino Benzoic Acid, } \\
\text { Anthranilic Acid and Succinic Acid }\end{array}$ & Dry grinding method. \\
\hline Darunavir & Succinic acid & Cooling crystallization & Solvent-drop grinding method \\
\hline Aceclofenac & Sodium Saccharin & Solvent evaporation & 69 \\
\hline Clarithromycin & Urea & $\begin{array}{l}\text { Dry grinding, liquid assisted } \\
\text { grinding (lag), solvent evaporation } \\
\text { se), and anti-solvent addition }\end{array}$ & 71 \\
\hline Paracetamol & Caffeine & $\begin{array}{l}\text { Solution crystallization based on } \\
\text { the ternary phase diagram } \\
\text { principle }\end{array}$ & 72 \\
\hline Myricetin & Proline & Solvent evaporation \\
\hline Efavirenz & Lactic acid and Adipic acid & $\begin{array}{l}\text { Kneading, solution crystallization, } \\
\text { antisolvent addition and solvent } \\
\text { drop grinding methods }\end{array}$ & 74 \\
\hline Fenofibrate & Nicotinamide & $\begin{array}{l}\text { Solution mediated phase } \\
\text { transformation }\end{array}$ \\
\hline Carbamazepine & Glucomannan & Solution crystallization \\
\hline danazol & vanillin & Wet co-grinding & 75 \\
\hline Felodipine & Xylitol & 76 \\
\hline
\end{tabular}




\begin{tabular}{|c|c|c|c|}
\hline Fexofenadine & Tartaric acid & Solvent evaporation & 78 \\
\hline Fenofibrate & Nicotinamide & $\begin{array}{l}\text { Solution cocrystallization } \\
\text { technique }\end{array}$ & 79 \\
\hline Fenofibrate & Saccharin, succinic acid, and sucrose & $\begin{array}{l}\text { Solution evaporation, slow } \\
\text { evaporation, antisolvent addition, } \\
\text { net grinding method, and solvent- } \\
\text { drop grinding methods }\end{array}$ & 80 \\
\hline Simvastatin- & Nicotinamide & Solvent evaporation & 81 \\
\hline Prulifloxacin & Salicylic acid & Solution crystallization technique & 82 \\
\hline Carbamazepine & Succinic acid & Solvent-drop grinding method & 83 \\
\hline Lornoxicam & Saccharin, salicylic acid, tartaric acid and pyrogallol & $\begin{array}{l}\text { Liquid assisted grinding, reaction } \\
\text { co-crystallization and cooling } \\
\text { crystallization }\end{array}$ & 84 \\
\hline Simvastatin & Aspartame & Slurry & 85 \\
\hline Mesalamine & Glutamine & Liquid assisted grinding & 86 \\
\hline Dipfluzine- & Benzoic acid & $\begin{array}{l}\text { Solvent-assisted co-grinding and } \\
\text { the solvent ultrasonic methods }\end{array}$ & 87 \\
\hline Simvastatin & Malic acid & Liquid assisted grinding & 88 \\
\hline Gliclazid & Succinic acid, Malic acid & Liquid assisted grinding & 89 \\
\hline Efavirenz & Fumaric acid & Neat grinding method & 90 \\
\hline Acyclovir & $\begin{array}{l}\text { Tartaric acid, succinic acid, malonic acid, glutaric acid, adipic } \\
\text { acid, citric acid, } 4 \text {-amino benzamide, } 4 \text {-hydroxy benzamide, } \\
\text { 4-amino benzoic acid, malic acid, oxalic acid, fumaric acid }\end{array}$ & $\begin{array}{l}\text { Solvent evaporation, wet grinding, } \\
\text { and an anti-solvent addition }\end{array}$ & 91 \\
\hline Diacerein & Urea and tartaric acid & Solvent drop grinding method & 92 \\
\hline Hesperetin & Picolinic acid, nicotinamide, and caffeine & Solvent drop grinding technique & 93 \\
\hline Ketoprofen & $\begin{array}{l}\text { Cinnamic acid, glutaric acid, maleic acid, malonic acid, } \\
\text { nicotinamide, oxalic acid, p-amino-benzoic acid, pamino } \\
\text { salicylic acid, saccharin and urea }\end{array}$ & Fusion method & 94 \\
\hline Theophylline & Acesulfame, saccharin & Solvent drop grinding method & 95 \\
\hline $\begin{array}{l}\text { Mefloquine } \\
\text { hydrochloride }\end{array}$ & $\begin{array}{l}\text { Benzoic acid citric acid, oxalic acid, saccharin, salicylic acid, } \\
\text { succinic acid, pure mefloquine tablets }\end{array}$ & Solution cocrystallization method & 96 \\
\hline
\end{tabular}

\section{REFERENCES}

1. Babu NJ and Nangia A. Solubility advantage of amorphous drugs and pharmaceutical cocrystals. Cryst Growth Des 2011; 11(26): 62-79.

2. Fong SYK, Ibisogly A, Bauer-Brandl A. Solubility enhancement of BCS class-II drug by solid phospholipid dispersions: Spray drying versus freeze-drying. Int J Pharm 2015; 496:382-91.

3. Jones W, Motherwell WDS, Trask AV. Pharmaceutical cocrystals: An Emerging approach to physical property enhancement. MRS Bull 2006; 31:875-879.

4. Zaworotko M. Crystal engineering of co-crystals and their relevance to pharmaceuticals and solid-state chemistry. Acta Cryst 2008; 64:11-12.

5. Rodríguez-Hornedo N, Nehm SJ, Jayasankar A, Cocrystals: design, properties and formation mechanisms, In Encyclopedia of Pharmaceutical Technology, 3rd ed, Taylor \& Francis, London, 2007; 615-635.

6. Schultheiss N, Newman A. Pharmaceutical co-crystals and their physicochemical properties. Cryst Growth Des.2009; 9:29502967.

7. Tiekink ERT, Vittal JJ (Editors). Frontiers in Crystal Engineering, John Wiley \& Sons, Ltd, 2006, Chapter 2: Crystal Engineering of Pharmaceutical Co-crystals, 25-50.

8. Vishweshwar P, McMahon JA, Bis JA, Zaworotko MJ. Pharmaceutical co-crystals J Pharm Sci 2006; 95:499-516.

9. Remenar JF, Morissette SL, Peterson ML, Moulton B, MacPhee JM, Guzmán H, Almarsson 0, Crystal engineering of novel cocrystals of a triazole drug with 1,4- dicarboxylic acids. J Am ChemSoc 2003; 125(8):456-8457.

10. Almarsson Ö, Zaworotko MJ. Crystal engineering of the composition of pharmaceutical phases. Do pharmaceutical cocrystals represent a new path to improved medicines? ChemCommun 2004; 1889-1896.

11. Morissette SL, Almarsson O, Peterson ML, Remenar JF, Read MJ, Lemmo AV, et al. High-throughput crystallization: polymorphs, salts, cocrystals and solvates of pharmaceutical solids. Adv Drug Deliv Rev 2004; 56:275-300.

12. Sekhon BS. Pharmaceutical cocrystals - An update. Chem Inform 2013; 44:62
13. Bolla G, Nangia A. Pharmaceutical cocrystals: walking the talk. ChemCommun 2016; 42-60.

14. Shan N, Zaworotko MJ. The role of cocrystals in pharmaceutical sciences. Drug Discov Today 2008; 13:440-46.

15. Abourahma H, Cocuzza DS, Melendez J, Urban JM. Pyrazinamide cocrystals and the search for polymorphs. CrystEngComm 2011; 13:1-22.

16. Batisai E, Ayamine A, Kilinkissa OEY, Bathori N. Melting pointsolubility-structure correlations in multicomponent crystal containing fumaric or adipic acid. Cryst Eng Comm 2014:16:9992-8.

17. Zhang H, Zhu Y, Qiao N, Chen Y, Gao L. Preparation and Characterization of Carbamazepine Cocrystal in Polymer Solution, Pharmaceutics 2017; 9:1-13

18. Jadhav A, Pore Y. Physiscochemical and micromeretics studies on Feofibrate cocrystal, Journal of pharm. Sci. tech. mgmt. 2016; 2(1)

19. Panzade P, Shendarkar G, Shaikh S, Rathi P. Pharmaceutical Cocrystal of Piroxicam: Design, Formulation and Evaluation. Adv Pharm Bull. 2017; 7(3):399-408

20. Zhouab Z, Lia W et al. Resveratrol cocrystals with enhanced solubility and tabletability. International Journal of Pharmaceutics. 2016; 509(1-2):391-399

21. Latif S, Abbas N, Hussain A, Arshad M S, Bukhari N I, Afzal H, Riffat S, Ahmad Z, Development of paracetamol-caffeine cocrystals to improve compressional, formulation and in vivo performance, Drug Development and Industrial Pharmacy, 2018; 44(7):1099-1108.

22. Mounika P, Vijaya Raj S, Divya1 G. A. Gowramma2 and G.Vijayamma3, Preparation and Characterization of Novel CoCrystal Forms of Fexofenadine, International Journal of Innovative Pharmaceutical Research. 2015; 6(1):458-463.

23. Sopyan I, Fudholi A, Muchtaridi M, Sari I P, Simvastatinnicotinamide co-crystal: design, preparation and preliminary characterization, Tropical Journal of Pharmaceutical Research. 2017; 16 (2):297-303

24. Chadha R, Saini A, Arora P, Chanda S, Jain D, Cocrystals Of Efavirenz With Selected Coformers: Preparation And 
Characterization, International Journal of Pharmacy and Pharmaceutical Sciences, 2012; 4(2).

25. Bagde SA, Upadhye KP, Dixit GR, Bakhle SS., Formulation and Evaluation of Co-Crystals of Poorly Water Soluble Drug, 2017.

26. Rajurkar VG, Aucharmal AL, Dethe S, Development of Ezogabine Co Crystal Formation: An Efficient Approach to Enhance Aqueous Solubility, British Biomedical Bulletin, 2015

27. Muddukrishna Bs, Dengale Sj. Shenoy Gg, Bhat, Preparation, Solid State Characterisation of Paclitaxel And Naringen Cocrystals With Improved Solubility, International Journal of Applied Pharmaceutics. 2016; 8(4).

28 Panzade P, Shendarkar G, Shaikh S, Rathi PB, Adv Pharm Bull,Pharmaceutical Cocrystal of Piroxicam: Design, Formulation and Evaluation 2017; 7(3):399-408

29. Muddukrishna BS, Aithal K, Pai A, Preparation, Solid State Characterization of Etraverine Co-Crystals with Improved Solubility for the Treatment of Human Immunodeficiency Virus International Journal of Pharmacological and Pharmaceutical Sciences. 2017; 11(1).

30. Gopi SP, Banik M, Desiraju GR. New Cocrystals of Hydrochlorothiazide: Optimizing Solubility and Membrane Diffusivity Crystal Growth \& Design. 2016.

31. Reddy MN, Anusha P. Development and Characterisation of Gliclazide Cocrystals International Journal of Pharmacy and Biological Sciences V2018; 8(1):22-32

32. Rahim SA, Rahman FANasir, ENEM., Ramle NA. Carbamazepine Co-crystal Screening with Dicarboxylic Acids Co-Crystal Formers International Journal of Chemical and Molecular Engineering. 2015; 9(5).

33. Gadade DD, Pekamwar SS, Lahot SR., Patn SD, Sarode MC. Cocrystallization of Etodolac: Prediction of Cocrystallization, Synthesis, Solid State Characterization and In Vitro Drug Release , Marmara Pharmaceutical Journal, 2017; 21:78-88.

34. Huang Y, Zhang B, Gao Y, Zhang J, Shi L. Nicotinamide Cocrystal with Enhanced Solubility, Dissolution, and Oral Bioavailability. 2014.

35. Rajbhar P, Sahu AK., Gautam SS., Prasad RK, Singh V, Nair SK Formulation and Evaluation of Clarithromycin CoCrystals Tablets Dosage Forms to Enhance the Bioavailability. The Pharma Innovation Journal. 2016; 5(6):05-13

36. Zhang $\mathrm{H}$, Zhu Y, Qiao N, Chen Y, Gao L, Preparation and Characterization of Carbamazepine Cocrystal in Polymer Solution, Pharmaceutics. 2017; 9(54):1-13

37. Jung S, Choi I, Kim W. Liquid-Assisted Grinding to Prepare a Cocrystal of Adefovir Dipivoxil Thermodynamically Less Stable than Its Neat Phase. Crystals 2015; 5:583-591

38. Othman MF, Jamburi N, Anuar N, Rahim SA, Rohalim NH Ibuprofen-amino acids co-crystal screening via co-grinding methods, MATEC Web Conf. 2016; 69

39. Payghan AS. Preparation and Characterization of Molecular Complexes of Fenofibrate Cocrystal. Asian Journal of Pharmaceutics. 2017; 11(4).

40. Setyawan D, Sari R, Yusuf H, Primaharinastiti R. Preparation and Characterization of Artesunate - Nicotinamide Cocrystal by Solvent Evaporation and Slurry Method. Asian J Pharm Clin Res, 2014; 7(1):62-65

41. Takata N, Shiraki K, Takano R, Hayashi Y, Terada K. Cocrystal Screening of Stanolone and Mestanolone Using Slurry Crystallization, Cryst. Growth De.2008; 8(8): 3032-3037

42. Apshingekar PP, Aher S, Kelly AL, Brown EC, Paradkar A. Synthesis of Caffeine/Maleic Acid Co-crystal by Ultrasoundassisted Slurry Co-crystallization, Journal of Pharmaceutical Sciences. 2017; 106(1):66-70

43. Erizal Z, Yeyet Cs, Sundani N S, Auzal H, Hidehiro U, Kotaro F, Cocrystalline Phase Transformation of Binary Mixture of Trimethoprim and Sulfamethoxazole by Slurry Technique, Asian Journal of Pharmaceutical and Clinical Research. 2010 $3(4)$.

44. Momoko N, Shoji K, Hiroshi T, Cocrystal production method reducing deposition risk of undesired single component crystals in anti-solvent cocrystallization, Journal of Industrial and Engineering Chemistry. 2016; 36:40-43

45. Chuna N, Wang I, Min-JL, Yun-Tk, Sangkil L, Woo SK, Guang JC, Characteristics of indomethacin-saccharin (IMC-SAC) cocrystals prepared by an anti-solvent crystallization process, European Journal of Pharmaceutics and Biopharmaceutics. 2013; 85(3):854-861
46. Jeong-WS, Kyu-MH, Sung-HL, Dong-WK. Preparation and characterization of adefovir dipivoxil-stearic acid cocrystal with enhanced physicochemical properties, Pharmaceutical Development and Technology. 2017.

47. Li S, Yu T, Tian Y, Lagan C, Jones DS, Andrews GP Mechanochemical Synthesis of Pharmaceutical Cocrystal Suspensions via Hot Melt Extrusion: Enhancing Cocrystal Yield. Mol Pharm. 2017.

48. Kevin B, Andrew O, Rodolfo P, Matrix-Assisted Cocrystallization (MAC) Simultaneous Production and Formulation of Pharmaceutical Cocrystals by Hot-Melt Extrusion. Journal of Pharmaceutical Sciences. 2014; 103(9):2904-2910

49 Kumar S, Nanda A. Pharmaceutical Cocrystals: An Overview, Indian J Pharm Sci 2017; 79(6):858-871

50. Apshingekar PP, Aher S, Kelly AL, Brown EC, Paradkar A Synthesis of Caffeine/Maleic Acid Co-crystal by Ultrasoundassisted Slurry Co-crystallization, Journal of Pharmaceutical Sciences. 2017; 106(1):66-70

51. Shikhar A, Mohan M, Simerdeep Singh B, Gupta E, Formulation development of Carbamazepine-Nicotinamide co-crystals complexed with $\gamma$-cyclodextrin using supercritical fluid process, The Journal of Supercritical Fluids. 2011; 55(3):1070-1078

52. Courtney A. Ober, Ram B. Gupta, Formation of ItraconazoleSuccinic Acid Cocrystals by Gas Antisolvent Cocrystallization, AAPS Pharm Sci Tech. 2012; 13(4):1396-1406.

53. Ning L, Binghui D, Xianming L, Minghui X, Qian Z, Bozhou W, Preparation of CL-20/DNDAP cocrystals by a rapid and continuous spray drying method: an alternative to cocrystal formation, crystengcomm, 2018.

54. Amjad A, Waseem K, Graham B, Hardyal G, Ali N, Sitaram P. Theophylline Cocrystals Prepared by Spray Drying: Physicochemical Properties and Aerosolization Performance, AAPS Pharm Sci Tech, 2013; 14(1).

55. Basavoju S, Bostrom D, Velaga SP. Indomethacin-saccharin cocrystal: Design, synthesis and preliminary pharmaceutical characterization. Pharm Res 2008; 25:530-541.,

56. Lu J, Rohani S. Preparation and characterization of theophylline - nicotinamide cocrystal. Org Process Res Dev, Article ASAP; 2009.

57 Zoghbi A., Wang B. Carvedilol solubility enhancement by inclusion complexation and solid dispersion: review. Journal of Drug Delivery and Therapeutics, 2015; 5(2):1-8.

58 Wenger M, Bernstein J. An alternate crystal form of gabapentin: A cocrystal with oxalic acid. Cryst Growth Des 2008; 8:15951598.

59. Vogt, FG, Clawson, JS. Strohmeier, M, Edwards, AJ, Solid-State NMR Analysis of Organic Cocrystals and Complexes. Cryst. Growth Des. 2009; 9:921-937.

60. Pindelska, E.; Sokal, A.; Kolodziejski, W. Pharmaceutical cocrystals, slats and polymorphs: Advanced characterization techniques. Adv. Drug Deliv. Rev. 2017; 1:111-146.

61. Paudel, A, Raijada D, Rantanen J. Raman spectroscopy in pharmaceutical product design. Adv. Drug Deliv. Rev. 2015; 89: 3-20

62. Langkilde, F.W. Sjoblom, J. Tekenbergs-Hjelte, L. Mrak, J. Quantitative FT-Raman analysis of two crystal forms of a pharmaceutical compound. J. Pharm. Biomed. Anal. 1997; 15:687-696

63. Hao Z, Ying Z, Ning Q, Yang C, Linghuan G, Preparation and Characterization of Carbamazepine Cocrystal in Polymer Solution, Pharmaceutics. 2017; 9(54):1-13

64. Shahram E, Khosro A, Mohammad B, Mohammadreza S. Piroxicam cocrystals with phenolic coformers: preparation, characterization, and dissolution properties Department of and characterized with Pharmaceutical and Food. 2017

65. Desai H, Rao L, Amin P, Carbamazepine Cocrystals by Solvent Evaporation Technique: Formulation and Characterization Studies American journal of pharmatech research, 2018

66. Fleischman SG, Kuduva SS, McMahon JA, Moulton B, Walsh RB, Rodriguez-Hornedo N, Zaworotko MJ. Crystal engineering of the composition of pharmaceutical phases. 2. Multiple component crystalline solids involving carbamazepine. Cryst Growth Des. 2003; 3:909-919.

67. Panzade P, Shendarkar G, Shaikh S, Rathi PB, Pharmaceutical Cocrystal of Piroxicam: Design, Formulation and Evaluation. Advanced Pharmaceutical Bulletin. 2017; 7(3):399-408

68. Bagde S A, Upadhye K P, Dixit G R, Bakhle S S, Formulation and Evaluation of Co-Crystals of Poorly Water Soluble Drug. 
International Journal of Pharmaceutical Research. 2016; 7(12):4988-4997.

69. Saxena M, Kuchekar BS, Cocrystal Formulation, Characterization, and Evaluation Study. International Conference on Advanced Nanomaterials \& Emerging Engineering technologies" (ICANMEET-20J3) New Deihl, India. 2013; 24(26):602-606

70. Rajbhar P, Sahu A K, Gautam S S, Prasad R K, Singh V, Nair S K, Formulation and Evaluation of Clarithromycin Co- Crystals Tablets Dosage Forms to Enhance the Bioavailability. The Pharma Innovation. 2016; 5(6):5-13

71. Latif S, Abbas N, Hussain A, Arshad M S, Bukhari N I, Afjal H, Development of Paracetamol-Caffeine Cocrystals to Improve Compressional, Formulation and In Vivo Performance. 2018; 44(7):1099-1108

72. Liu M , Hong C, Yao Y, Shen H, Ji G , Li G , Xie Y. Development of a Pharmaceutical Cocrystal With Solution Crystallization Technology: Preparation, Characterization, and Evaluation of Myricetin-Proline Cocrystals. European Journal of Pharmaceutics and Biopharmaceutics. 2016; 107:151-159

73. Rajurkar V G, Nagare A M, Ghawate V, Tablet Formulation and Enhancement of Aqueous Solubility of Efavirenz by Solvent Evaporation Co-Crystal Technique. Med chem, an open access journal. 2015

74. Shewale S, Shete A S, Doijad R C, Kadam S S, Patil V A, Yadav A V, Formulation and Solid State Characterization of Nicotinamidebased Co-crystals of Fenofibrate. Indian Journal of Pharmaceutical Sciences. 2015; 77(3):328-334

75. Hardikar S, Bhosale A, Vanave S, Kamathe B, Preparation and Evaluation OF Co-Crystals of Carbamazepine with Glucomannan. International Journal of Pharmacy and Pharmaceutical Sciences.2017; 9(10):318-320

76. Childs S L, Kandi P, Lingireddy S R,Formulation of a Danazol Cocrystal with Controlled Supersaturation Plays an Essential Role in Improving Bioavailability. 10:3112-3127

77. Arafa M F, El-Gizawy S A, Osman MA, \& Maghraby GM, Xylitol as a potential co-crystal co-former for enhancing dissolution rate of felodipine: preparation and evaluation of sublingual tablets. Pharmaceutical Development and Technology. 2016

78. Mounika P, Raj1 V S, Divya1 G, Gowramma A, Vijayamma G, Preparation and Characterization of Novel Co-Crystal Forms of Fexofenadine. International Journal of Innovative Pharmaceutical Research. 2015; 6(1):458-463

79. Shete A S, Khandagale V V, Murthy M, Yadav A V, Sakhre S S, Doijad R C, Solid State Characterization and Tableting Studies of Ethanol Based Cocrystals of Fenofibrate with Nicotinamide. Indian Journal of Pharmaceutical Education and Research. 2018; 51(2):71-77

80. Gaikwad E R, Khabade S S, Sutar T B, Payghan S A, Preparation and Characterization of Molecular Complexes of Fenofibrate Cocrystal. Asian Journal of Pharmaceutics. 2017; 11(4):S745S759

81. Sopyan I, Fudholi A, Muchtaridi M, Puspita Sari I, Simvastatinnicotinamide co-crystal: design, preparation and preliminary characterization. Tropical Journal of Pharmaceutical Research. 2017; 16(2):297-303

82. Tamkhane V V, Design and Development of Prulifloxacin Formulations by Co-Crystallization Technique. International Journal of Pharma Sciences and Research. 2015; 6(8):11461155

83. Ullah M, Ullah H, Murtaza G, Qaisar Mahmood Q, Hussain I, Evaluation of Influence of Various Polymers on Dissolution and Phase Behavior of Carbamazepine-Succinic Acid Cocrystal in Matrix Tablets. BioMed Research International

84. Patel D M, Shah H R, Patel R J, Patel C, Preparation and Characterization Of Lornoxicam Co-Crystals. World Journal of Pharmacy and Pharmaceutical Sciences. 2014; 3(6):713-732

85. Kharisma R M, Sopyan I, Dissolution Rate Repairing of Simvastatin as A New Approach in Cocrystallization. Der Pharmacia Lettre. 2017; 9(6):18-27

86. Mamatha T, Sama M, Queshi H K, Development and evaluation of Mesalamine- Glutamine Cocrystal Tablets for Colon Specific Delivery. 2017; 10(5):3866-3874

87. Lin Y, Yang H, Yang C, Wang J, Preparation, Characterization, and Evaluation of Dipfluzine-Benzoic Acid Cocrystals with Improved Physicochemical Properties. 2013; 31(3):566-578

88. Sopyan I, Fudholi A, Muchtaridi M, Puspitasari I, A Novel of Cocrystalization to Improve Solubility and Dissolution rate of Simvastatin. International Journal of PharmTech Research. 2016; 9(6):483-491

89. Chadha R, Rani D, Goyal P, Novel Cocrystals of Gliclazide: Characterization and Evaluation. Crystengcomm. 1-19

90. Gadade DD, Pekamwar SS, Shirsat MD, Crystal Engineering of Antiviral Agent Efavirenz for Solubility Enhancement. Journal of Drug Delivery and Therapeutics. 2018; 8(1):86-91

91. Savjani JK, Pathak C, Improvement of Physicochemical Parameters of Acyclovir using Cocrystallization Approach. Brazilian Journal of Pharmaceutical Sciences. 2016; 52(4):727734

92. Thenge RR, Patond V B, Adhao VS, Ajmire PV, Barde LN, Mahajan N M, Tekade N P, Preparation and Characterization of CoCrystals of Diacerein. 2017; 28(1):34-41

93. Chadha K, Karan K, Bhalla Y, Chadha R, Khullar S, Mandal S, Vasisht K, Cocrystals of Hesperetin: Structural, Pharmacokinetic, and Pharmacodynamic Evaluation. Crystal Growth \& Design. 2017; 17(5): 2386-2405

94. Vaghela R, Kulkarni PK, Hani U, Varma VNSK, Raizaday A, Enhancing Aqueous Solubility of Ketoprofen by Fusion Technique Using Suitable Co-formers. Current Drug Therapy. 2014; 9(3):199- 207

95. Aitipamula S, Wong ABH, Kanaujia P, Evaluating Suspension Formulations of Theophylline Cocrystals with Artificial Sweeteners. Journal of Pharmaceutical Sciences. 2017;1-30

96. Shete AS, Yadav AV, Murthy MS, Evaluation of performance of co crystals of mefloquine hydrochloride in tablet dosage form. Drug Development and Industrial Pharmacy Informa Health care. 2013 ; 39(5):716-723 